\title{
Article
}

\section{Lipoprotein lipase gene variants relate to presence and degree of microalbuminuria in Type II diabetes}

\author{
R. K. Mattu ${ }^{1,2}$, J. Trevelyan ${ }^{2}$, E. W. A. Needham ${ }^{2}$, M. Khan², M. A. Adiseshiah ${ }^{3}$, D. Richter ${ }^{2}$, R. G. Murray ${ }^{3}$, \\ D. J. Betteridge ${ }^{3}$ \\ ${ }^{1}$ Department of Cardiology, University Hospitals Coventry and Warwickshire NHS Trust, Clifford Bridge Road, Coventry, UK \\ ${ }^{2}$ Cardiovascular Genetics, Department of Biological Sciences, University of Warwick and University Hospitals of Coventry \\ and Warwickshire, Warwickshire, UK \\ 3 The Rayne Institute, University College London Medical School, London, UK
}

\section{Abstract}

Aims/hypothesis. Lipids and lipoproteins, particularly triglyceride rich lipoproteins, could influence the development and progression of microalbuminuria in diabetes. Lipoprotein lipase gene variants have been found to correlate with lipid/lipoprotein concentrations, especially hypertriglyceridaemia. We assessed the influence of this gene on microalbuminuria in Type II (insulin-dependent) diabetes mellitus.

Methods. Microalbuminuria was determined quantitatively in 386 sequential Type II diabetic patients by measurement of the albumin-to-creatinine ratio (ACR). DNA was analysed for two common intronic LPL single nucleotide polymorphisms (Pvu II, intron 6, and Hind III, intron 8), and three common exonic mutations (Asp9-Asn, exon 2, Asn ${ }^{291}$-Ser, exon 6, and Ser ${ }^{447}$-Ter, exon 9).

Results. Individuals with $\mathrm{P}_{2} \mathrm{P}_{2}$ (Pvu II) and $\mathrm{H}_{2} \mathrm{H}_{2}$ (Hind III) genotypes had significantly greater ACRs $\left(P_{2} P_{2}\right.$ vs $P_{1} P_{1}+P_{1} P_{2}, 5.0 \pm 0.5$ vs $3.4 \pm 0.3, p=0.0004$ and $H_{2} H_{2}$ vs
$H_{1} H_{1}+H_{1} H_{2}, 4.3 \pm 0.4$ vs $\left.3.4 \pm 0.3, p=0.04\right)$. Logistic regression analysis demonstrated that only the $P_{2} P_{2}$ genotype $(p=0.0004)$, systolic $\mathrm{BP}(p=0.008)$ and creatinine $(p=0.031)$ were independently associated with the presence of microalbuminuria/proteinuria. $P_{2}$ homozygotes were $170 \%$ more likely to have microalbuminuria or proteinuria, O.R. $2.7(1.6-4.5, p=0.0001)$, $150 \%$ more likely to have microalbuminuria, O.R. 2.5 $(1.5-4.3, p=0.001)$, and $330 \%$ more likely to have proteinuria, O.R. $4.3(1.6-11.4, p=0.004)$. There were no associations of microalbuminuria with any of the exonic polymorphisms.

Conclusion/interpretation. Genetic variants of lipoprotein lipase correlate with presence and severity of microalbuminuria in Type II diabetes, independent of effect on serum lipids. This association is only apparent in genetic variants demonstrating greatest heterozygosity. [Diabetologia (2002) 45:905-913]

Keywords Lipoprotein lipase gene, microalbuminuria, Type II diabetes.
Diabetic nephropathy (DN) affects about $30 \%$ of Type I (non-insulin-dependent) and 25-60\% of Type II (in-

Received: 3 October 2001 / Revised: 31 January 2002

Published online: 23 May 2002

(C) Springer-Verlag 2002

Corresponding author: Dr. R. K. Mattu, Department of Cardiology, University Hospitals Coventry and Warwickshire NHS Trust, Clifford Bridge Road, Coventry, CV2 2DX, UK, e-mail: raj.mattu@wh-tr.wmids.nhs.uk

Abbreviations: ACR, Albumin:ceatinine ratio; LPL, lipoprotein lipase; DN, diabetic nephropathy; MA, microalbuminuria; ESRD, end-stage renal disease; HDL-C, high density lipoprotein cholesterol; NA, normoalbuminuria; AER, albumin excretion rate sulin-dependent) diabetic patients with substantial racial variation in prevalence [1], which suggests genetic determinants. Microalbuminuria (MA) is an early marker of diabetic renal disease [2,3] and predicts progression to proteinuria and end-stage renal failure in Type I $[4,5]$ and probably Type II patients $[6,7]$. It is also associated with excess mortality in both groups, especially from cardiovascular disease $[8,9]$. Why some patients develop MA and why this progresses at variable rates to end-stage renal disease (ESRD) is not clear, but DN accounts for about $35 \%$ of new cases of ESRD [10].

It is commonly accepted that microalbuminuria is relevant to DN in Type II diabetes [7], even though 
some authors question the specificity of proteinuria for $\mathrm{DN}$ in Type II diabetes, and the dose-response relationship between glycaemia and DN has not been shown in Type II diabetes. The similarities between Type I and Type II diabetes justify examination of the cause of DN in both diseases.

Consideration of hereditary factors predisposing certain individuals to $\mathrm{DN}$ is supported by familial studies in a number of ethnic populations $[11,12,13]$. A role for lipids in the development and progression of renal failure [14] was subsequently supported by animal experimental models of renal insufficiency [15], and observational studies in diabetic and non-diabetic humans $[16,17,18,19,20,21]$. This relationship could be more pronounced with triglyceride-rich lipoproteins which contain apo-B100, such as VLDL and IDL [22].

Lipoprotein lipase (LPL), a hydrolytic enzyme bound to the vascular endothelium, is a rate limiting enzyme for the clearance of triglyceride-rich lipoproteins from the circulation, from both exogenous (chylomicrons) and endogenous (VLDL) sources [23]. We and others have previously found that genetic variants of LPL relate to dyslipidaemia and atherosclerosis, including concentrations of triglycerides $[24,25,26,27,28,29]$, high density lipoprotein cholesterol (HDL-C) [24, 25, 30, 31, 32], and total cholesterol [25, 29, 31], development [24, 25, 33] and severity $[24,26]$ of coronary artery disease, familial combined hyperlipidaemia $[34,35]$ and familial chy- lomicronaemia [36]. Recently, no relationship was found between an exonic LPL polymorphism and Type I diabetic nephropathy [37], although a potent effect of total cholesterol, triglycerides and apo-B was noted on DN.

We therefore investigated whether the LPL gene influences microalbuminuria in Type II diabetic patients.

\section{Subjects and methods}

Patients. Altogether 386 men and women with Type II diabetes consecutively attending the diabetes clinic were specifically recruited for our study to undergo detailed clinical characterisation and genetic analysis. A clinical diagnosis of Type II diabetes was made according to World Health Organisation (WHO) criteria, and all such consenting patients were enrolled, only excluding those with other renal pathologies which could influence microalbuminuria. Hypertension was defined as a sitting office blood pressure of more than 140/90 on two occasions or use of anti-hypertensive medication; hypercholesterolaemia was defined as total cholesterol $>5.0 \mathrm{mmol} / \mathrm{l}$ or use of lipid lowering medication; current smoking was defined as any regular use of tobacco products during the previous month.

Although the pre-diagnosis duration of Type II diabetes is often not clear, and the diagnosis could only be discovered due to symptomatology or opportunistic screening, it would appear appropriate to utilise the earliest assessment of MA after diagnosis, before the confounding effects of treatment for hypertension/lipids or duration of follow-up. We therefore correlated the earliest available demographic and clinical (including MA) data following diagnosis with genotypic data, see Table 1. MA had been determined quantitatively, with the patient clinically

Table 1. Demographic details of the study cohort

\begin{tabular}{|c|c|c|c|c|c|}
\hline & \multicolumn{5}{|c|}{ Means \pm SEMs } \\
\hline & $\begin{array}{l}\text { Whole cohort } \\
(n=386)\end{array}$ & $\begin{array}{l}\text { Caucasian } \\
(n=266)\end{array}$ & $\begin{array}{l}\text { Non-Caucasian } \\
(n=120)\end{array}$ & $\begin{array}{l}\text { Males } \\
(n=226)\end{array}$ & $\begin{array}{l}\text { Females } \\
(n=160)\end{array}$ \\
\hline Male/female & $226 / 160$ & $149 / 117$ & $77 / 43$ & - & - \\
\hline Age (years) & $63.2 \pm 0.6$ & $65.4 \pm 0.8$ & $58.2 \pm 1.0^{\mathrm{a}}$ & $62.3 \pm 0.8$ & $64.4 \pm 1.0$ \\
\hline BMI $\left(\mathrm{kg} / \mathrm{m}^{2}\right)$ & $28.8 \pm 0.3$ & $29.6 \pm 0.4$ & $27.0 \pm 0.4^{\mathrm{b}}$ & $28.3 \pm 03$ & $29.4 \pm 0.5$ \\
\hline Hypertension (\%) & $32.1 \%$ & $29.5 \%$ & $38.1 \%$ & $29.7 \%$ & $35.5 \%$ \\
\hline Hypercholesterolaemia (\%) & $20.0 \%$ & $21.4 \%$ & $16.7 \%$ & $18.5 \%$ & $22.1 \%$ \\
\hline Smoking $(\%)$ & $21.8 \%$ & $24.9 \%$ & $14.1 \% \mathrm{c}^{\mathrm{c}}$ & $26.5 \%$ & $14.7 \%$ \\
\hline Diabetes Duration (years) & $13.6 \pm 0.5$ & $13.7 \pm 0.7$ & $13.4 \pm 0.8$ & $13.5 \pm 0.7$ & $13.7 \pm 0.9$ \\
\hline Systolic BP (mmHg) & $138.8 \pm 1.1$ & $139.2 \pm 1.3$ & $137.9 \pm 2.0$ & $138.7 \pm 1.3$ & $138.5 \pm 1.9$ \\
\hline Diastolic BP (mmHg) & $79.6 \pm 0.6$ & $79.5 \pm 0.7$ & $79.8 \pm 1.1$ & $80.5 \pm 0.8$ & $78.3 \pm 1.0$ \\
\hline Cholesterol (mmol/l) & $5.7 \pm 0.1$ & $5.8 \pm 0.1$ & $5.5 \pm 0.1^{\mathrm{d}}$ & $5.5 \pm 0.1$ & $6.0 \pm 0.1$ \\
\hline $\mathrm{HDL}-\mathrm{C}(\mathrm{mmol} / \mathrm{l})$ & $1.23 \pm 0.02$ & $1.26 \pm 0.03$ & $1.16 \pm 0.04 \mathrm{e}$ & $1.16 \pm 0.03$ & $1.32 \pm 0.04$ \\
\hline Triglycerides (mmol/l) & $2.5 \pm 0.1$ & $2.6 \pm 0.1$ & $2.5 \pm 0.1$ & $2.5 \pm 0.1$ & $2.6 \pm 0.1$ \\
\hline Creatinine $(\mathrm{mg} / \mathrm{dl})$ & $107.1 \pm 2.1$ & $109.6 \pm 2.8$ & $101.8 \pm 2.8$ & $115.1 \pm 3.1$ & $95.6 \pm 2.1$ \\
\hline $\mathrm{HbA}_{1}(\mathrm{~g} / \mathrm{l})$ & $9.7 \pm 0.1$ & $9.6 \pm 0.2$ & $9.9 \pm 0.2$ & $9.6 \pm 0.1$ & $10.0 \pm 0.2$ \\
\hline Normoalbuminuria $(n)$ & 155 & 112 & 43 & 81 & 74 \\
\hline Microalbuminuria $(n)$ & 142 & 94 & 48 & 84 & 58 \\
\hline Proteinuria $(n)$ & 20 & 13 & 7 & 18 & 2 \\
\hline $\begin{array}{l}\text { Urinary ACR (excluding } \\
\text { proteinurics, } \mathrm{mg} / \mathrm{mmol} \mathrm{Cr} \text { ) }\end{array}$ & $3.9 \pm 0.2$ & $3.8 \pm 0.3$ & $4.1 \pm 0.4$ & $3.3 \pm 0.3$ & $4.5 \pm 0.4$ \\
\hline
\end{tabular}

a Caucasians vs Non-Caucasians, $p<0.0001$

b Caucasians vs Non-Caucasians, $p<0.0001$

c Caucasians vs Non-Caucasians, $p=0.054$ d Caucasians vs Non-Caucasians, $p=0.016$

e Caucasians vs Non-Caucasians, $p=0.02$ 
Table 2. Genotypic and allelic distributions and frequencies (bracketed)

\begin{tabular}{|c|c|c|c|c|c|c|c|c|}
\hline & \multicolumn{4}{|l|}{ Genotype } & \multicolumn{2}{|l|}{ Allele } & \multirow{2}{*}{$\begin{array}{l}\text { Hardy-Weinberg } \\
\chi^{2}(p)\end{array}$} & \multirow{2}{*}{$\begin{array}{l}\text { Hetero- } \\
\text { zygosity } \\
\text { Index }\end{array}$} \\
\hline & $P_{1} P_{1}$ & $P_{1} P_{2}$ & $P_{2} P_{2}$ & $P_{1} P_{1}+P_{1} P_{2}$ & $P_{1}$ & $P_{2}$ & & \\
\hline Whole group & $88(0.24)$ & $169(0.46)$ & $111(0.30)$ & $257(0.70)$ & $345(0.47)$ & $391(0.53)$ & $0.0059(0.9)$ & 0.498 \\
\hline Caucasians & $55(0.23)$ & $107(0.44)$ & $79(0.33)$ & $162(0.67)$ & $217(0.45)$ & $265(0.55)$ & $0.0123(0.9)$ & \\
\hline Non-Caucasians & $32(0.29)$ & $52(0.46)$ & $28(0.25)$ & $84(0.75)$ & $116(0.52)$ & $108(0.48)$ & $0.0062(0.9)$ & \\
\hline Whole group & $23(0.06)$ & $143(0.39)$ & $205(0.55)$ & $166(0.45)$ & $189(0.25)$ & $553(0.75)$ & $0.001(1.0)$ & \multirow[t]{3}{*}{0.375} \\
\hline Caucasians & $14(0.06)$ & $97(0.40)$ & $132(0.54)$ & $111(0.46)$ & $125(0.26)$ & $361(0.74)$ & $0.0016(1.0)$ & \\
\hline Non-Caucasians & 7 (0.06) & $41(0.36)$ & $65(0.58)$ & $48(0.42)$ & $55(0.24)$ & $171(0.76)$ & $0.0002(1.0)$ & \\
\hline Ser ${ }^{447}-\mathrm{Ter}$ & $C C$ & $C G$ & $G G$ & $C G+G G$ & $C$ & $G$ & & 0.180 \\
\hline$A s p^{9}-A s n$ & $G G$ & $G A$ & $A A$ & $G A+A A$ & $G$ & $A$ & & \multirow{4}{*}{0.075} \\
\hline Whole group & $332(0.914)$ & $30(0.083)$ & $1(0.003)$ & $31(0.086)$ & $694(0.96)$ & $32(0.04)$ & $0.0018(1.0)$ & \\
\hline Caucasians & $217(0.916)$ & $19(0.80)$ & $1(0.004)$ & $20(0.084)$ & $434(0.96)$ & $21(0.04)$ & $0.0038(1.0)$ & \\
\hline Non-Caucasians & $101(0.91)$ & $10(0.09)$ & 0 & $10(0.09)$ & $212(0.95)$ & $10(0.05)$ & $0.0028(1.0)$ & \\
\hline Asn ${ }^{291}-S e r$ & $R_{1} R_{1}$ & $R_{1} R_{2}$ & $R_{2} R_{2}$ & $R_{1} R_{2}+R_{2} R_{2}$ & $R_{1}$ & $R_{2}$ & & \multirow{4}{*}{0.020} \\
\hline Whole group & $373(0.98)$ & $9(0.02)$ & 0 & $9(0.02)$ & $755(0.99)$ & $9(0.01)$ & $0.0001(1.0)$ & \\
\hline Caucasians & $243(0.96)$ & $9(0.04)$ & 0 & $9(0.04)$ & $495(0.98)$ & $9(0.02)$ & $0.0004(1.0)$ & \\
\hline Non-Caucasians & 115 & 0 & 0 & 0 & 230 & 0 & - & \\
\hline
\end{tabular}

well, afebrile and with stable diabetic control, from measurement of the albumin:creatinine ratio (ACR) on random spot urine samples and defined by a ratio between $2.0-20 \mathrm{mg} / \mathrm{mmol}$ $\mathrm{Cr}$ (men) and $2.8-28 \mathrm{mg} / \mathrm{mmol} \mathrm{Cr}$ (women). ACR was measured by an immunoturbidimetric assay with a Cobas Bio or Cobas Integra analyser (Roche Diagnostics, Lewes, East Sussex, England). Coefficient of variation of the assay was $3.8 \%$ at $13.8 \mathrm{mg}$ and $0.2 \%$ at $86.9 \mathrm{mg}$. All genetic analyses were done anonymously after informed consent, with approval from the local ethics committee.

DNA analysis. DNA was isolated from frozen EDTA whole blood and genotyped for single nucleotide polymorphisms in intron 6 (Pvu II) and intron 8 (Hind III) as described elsewhere [24]. This yields $P_{2}$ and $H_{2}$ alleles in the presence of restriction sites. Coding sequence polymorphisms in exon 2 (Asp9-Asn), 6 (Asn ${ }^{291}$-Ser) and 9 (Ser ${ }^{447}$-Ter) were genotyped as previously described [24, 32, 38], yielding alleles $G$ and $A, R_{1}$ and $R_{2}$, and $C$ and $G$ respectively in the presence and absence of the restriction sites (Table 2).

Statistical analysis. Statistical analyses were done using the SPSS version 7.5 for Windows and S-Plus (MathSoft Inc) statistical packages. Discrete variables were analysed with Fisher's exact test. Continuous variables were analysed with Student's $t$ test for variables with a normal distribution, and MannWhitney U test or Kruskal-Wallis test for those with a nonparametric distribution. Multiple regression analyses were done to ascertain which factors were predictive of microalbuminuria, independent of potential confounding variables. Binary logistic regression analysis was performed utilising normoalbuminuria versus MA/proteinuria, by an enter model. Linear regression was performed utilising microalbuminuria as a continuous vari- able by an enter model. Covariates analysed were age, systolic $\mathrm{BP}$, diastolic $\mathrm{BP}$, duration of diabetes, $\mathrm{HbA}_{1}$, total cholesterol, HDL-C, triglycerides and serum creatinine, entered as continuous variables. Binary variables included smoking, gender and genotype. Patients homozygous for the $P_{2}$ allele were compared with all individuals possessing the $P_{1}$ allele. Substitution for missing data was performed on continuous variables using the mean of available values, and for discrete variables we simulated data from a uniform distribution and assigned a value of 0 or 1 to the missing data, depending on whether the actual proportion in the variable is less or greater than a random number (as advised by Statistical Consultancy Unit, Department of Statistics, University of Warwick).

Power calculations demonstrated that using the standard deviation of ACR measurements in our institute, a cohort of 267 would be required to detect a $30 \%$ difference with $80 \%$ power at the $5 \%$ significance level, and a cohort of 385 to detect a $25 \%$ difference. As there was no published data examining the effect of the LPL gene on microalbuminuria in Type II diabetes on which to base these analyses, these calculations predicted a nominal effect size, which could be observed with any of the genetic polymorphisms investigated.

\section{Results}

Patient demographics (Table 1) reveal that Caucasians were significantly older, showed a trend toward more frequent smoking, had higher BMI, total cholesterol and HDL-C. Females were older, less likely to be current smokers, had higher total cholesterol and HDL-C, lower diastolic BP and creatinine. Females were also 
less likely to have proteinuria, but had higher ACRs, excluding proteinurics. ACR measurements were available in 317 patients. $19.7 \%$ of the cohort had a serum creatinine above the reference range for our institute. The non-Caucasian group was ethnically heterogenous, being made up of Indian-Asians $(n=43$, $11.1 \%)$, South-East Asians $(n=40,10.4 \%)$, African/Afro-Caribbeans $(n=30,7.8 \%)$ and others $(n=7$, $1.8 \%)$. There were no differences in any of these demographic factors by genotype (data not shown).

The genotype and allele frequencies were in HardyWeinberg equilibrium in the whole cohort and ethnic sub-groups which also includes the calculated heterozygosity indices (Table 2). Despite repeated attempts, $15(3.9 \%)$ samples could not be analysed for Hind III, $18(4.7 \%)$ for Pvu II, 25 (6.5\%) for Asp9-Asn, 17 (4.4\%) for Asn ${ }^{291}$-Ser and 15 (3.9\%) for Ser ${ }^{447}$-Ter. The Hind III and Pvu II polymorphisms were in linkage disequilibrium $(p<0.0001)$, and both were in linkage disequilibrium with the exon 9 coding sequence mutation $(p<0.0001)$. Of the exonic mutations, the $A$ allele (Asp ${ }^{9}$-Asn) was observed in $4 \%$ of the population, the $R_{2}$ allele (Asn ${ }^{291}-\mathrm{Ser}$ ) in only $1 \%$ of the whole cohort and $2 \%$ of Caucasians, and the $G$ allele (Ser ${ }^{447}$-Ter) in $10 \%$ of the full cohort and $11 \%$ of Caucasians. We found no associations between any of these exonic alleles and microalbuminuria (data not shown).

A small number of patients $(n=20)$ had ACRs in the proteinuric range, and although arbitrary thresholds define this group from microalbuminuria, analysis was done both including and excluding these patients to evaluate their influence upon our observations. Examination of these ACR values by Pvu II and Hind III genotypes within the whole cohort, and Caucasians as the largest sub-group, indicates that those subjects possessing the $P_{1}$ and $H_{1}$ allele have broadly similar mean ACR concentrations, while $\mathrm{P}_{2} \mathrm{P}_{2}$ and $\mathrm{H}_{2} \mathrm{H}_{2}$ homozygotes have significantly higher mean concentrations (Table 3 ). This suggests a recessive effect of the $\mathrm{P}_{2}$ and $\mathrm{H}_{2}$ alleles, rather than a gene dose effect. Consequently, subsequent analyses were done comparing subjects homozygous for these recessive alleles with those possessing the $P_{l}$ and $H_{1}$ alleles. Further support for this observation was derived from our findings whereby only a minority of patients who were homozygous for the recessive alleles had normoalbuminuria, in contrast to alternative genotypes who exhibited similar categorical distributions (Table 5).

Urinary ACRs by genotype, excluding proteinurics, are shown in Table 3. Individuals homozygous for the $P_{2}$ allele had a significantly elevated mean ACR $\left(P_{2} P_{2}\right.$ vs $P_{1} P_{1}+P_{1} P_{2}, 5.0 \pm 0.5$ vs $\left.3.4 \pm 0.3, p=0.0004\right)$. Due to potential increase in genetic heterogeneity introduced by the non-Caucasian sub-group, we also explored the genotypic relationships within the Caucasian group. Our power calculations before the study gave us an $80 \%$ power of detecting a $30 \%$ difference in ACR
Table 3. PvuII and HindIII polymorphisms and Albumin:Creatinine ratios, excluding proteinurics

\begin{tabular}{lllll}
\hline & \multicolumn{4}{c}{ ACR $(\mathrm{mg} / \mathrm{mmol} \mathrm{Cr})$ mean $\pm \mathrm{SEM}$} \\
\hline & $P_{1} P_{1}$ & $P_{1} P_{2}$ & $P_{2} P_{2}$ & $P_{1} P_{1}+P_{1} P_{2}$ \\
Whole cohort & $3.6 \pm 0.5$ & $3.3 \pm 0.3$ & $5.0 \pm 0.5$ & $3.4 \pm 0.3^{\mathrm{a}}$ \\
Caucasians & $3.4 \pm 0.6$ & $2.9 \pm 0.4$ & $5.1 \pm 0.6$ & $3.1 \pm 0.3^{\mathrm{b}}$ \\
Male Caucasians & $3.1 \pm 0.7$ & $2.8 \pm 0.5$ & $4.4 \pm 0.7$ & $2.9 \pm 0.4^{\mathrm{c}}$ \\
Female Caucasians & $3.7 \pm 1.1$ & $3.2 \pm 0.7$ & $5.8 \pm 0.9$ & $3.4 \pm 0.6^{\mathrm{d}}$ \\
Non-Caucasian & $3.9 \pm 1.0$ & $3.9 \pm 0.6$ & $4.7 \pm 1.0$ & $3.9 \pm 0.5$ \\
& & & & \\
Whole cohort & $H_{1} H_{1}$ & $H_{1} H_{2}$ & $H_{2} H_{2}$ & $H_{1} H_{1}+H_{1} H_{2}$ \\
Caucasians & $3.3 \pm 0.9$ & $3.4 \pm 0.4$ & $4.3 \pm 0.4$ & $3.4 \pm 0.3^{\mathrm{e}}$ \\
Male Caucasians & $3.4 \pm 1.1$ & $3.4 \pm 0.4$ & $4.1 \pm 0.4$ & $3.4 \pm 0.4$ \\
Female Caucasians & $2.4 \pm 0.7$ & $3.8 \pm 0.7$ & $5.0 \pm 0.8$ & $3.6 \pm 0.6^{\mathrm{f}}$ \\
Non-Caucasian & $2.8 \pm 1.7$ & $3.6 \pm 0.6$ & $4.5 \pm 0.7$ & $3.5 \pm 0.6$ \\
\hline
\end{tabular}

a $P_{1} P_{1}+P_{1} P_{2}$ vs $P_{2} P_{2}$ (199 vs 84$), p=0.0004$

b $P_{1} P_{1}+P_{1} P_{2}$ vs $P_{2} P_{2}$ (133 vs 63), $p=0.0003(p=0.001)$

${ }^{c} P_{1} P_{1}+P_{1} P_{2}$ vs $P_{2} P_{2}$ (74 vs 31$), \mathrm{p}=0.01(p=0.05)$

d $P_{1} P_{1}+P_{1} P_{2}$ vs $P_{2} P_{2}$ (59 vs 32$), p=0.01(p=0.04)$

e $H_{1} H_{1}+H_{1} H_{2}$ vs $H_{2} H_{2}(133$ vs 152$), p=0.04$

f $H_{1} H_{1}+H_{1} H_{2}$ vs $H_{2} H_{2}$ (47 vs 45$), p=0.053(p=0.2)$

Values in brackets are corrected for multiple analyses with Bonferroni's correction

amongst Caucasians ( $n=266)$, but the statistical power to examine the relationships in non-Caucasians $(n=120)$ was not adequate. Caucasian $P_{2}$ homozygotes had a higher mean ACR $\left(P_{2} P_{2}\right.$ vs $P_{1} P_{1}+P_{1} P_{2}, 5.1 \pm 0.6$ vs $3.1 \pm 0.3, p=0.0003)$, which was observed in Caucasian men $(4.4 \pm 0.7$ vs $2.9 \pm 0.4, p=0.01)$ and women $(5.8 \pm 0.9$ vs $3.4 \pm 0.6, p=0.01)$. A similar trend was seen in the non-Caucasians. Likewise, individuals homozygous for the $\mathrm{H}_{2}$ allele had a higher mean ACR $\left(\mathrm{H}_{2} \mathrm{H}_{2}\right.$ vs $H_{1} H_{1}+H_{1} H_{2}, 4.3 \pm 0.4$ vs $3.4 \pm 0.3, p=0.04$ ), which was also observed in all subgroups. All but two of these analyses remain significant after correction for multiple analysis using Bonferroni's correction (see Table 3).

These comparisons were repeated after including patients whose ACR was in the proteinuric range, as shown in Table 4 . Individuals homozygous for the $P_{2}$ allele had a higher mean ACR $\left(P_{2} P_{2}\right.$ vs $P_{1} P_{1}+P_{1} P_{2}$, $12.6 \pm 3.5$ vs $6.0 \pm 1.1, p<0.0001)$. This was observed amongst the Caucasians $(10.8 \pm 3.6$ vs $5.8 \pm 1.4$, $p=0.0001)$, including males $(14.2 \pm 6.7$ vs $5.8 \pm 1.7$, $p=0.005)$ and females $(7.2 \pm 1.6$ vs $5.8 \pm 2.5, p=0.01)$. Again, a similar trend was seen in the non-Caucasians. Likewise, individuals homozygous for the $\mathrm{H}_{2}$ allele had a higher mean ACR $\left(\mathrm{H}_{2} \mathrm{H}_{2}\right.$ vs $\mathrm{H}_{1} \mathrm{H}_{1}+\mathrm{H}_{1} \mathrm{H}_{2}, 9.2 \pm 1.9$ vs $6.4 \pm 1.7, p=0.02)$. This was observed in Caucasians $\left(\mathrm{H}_{2} \mathrm{H}_{2}\right.$ vs $\mathrm{H}_{1} \mathrm{H}_{1}+\mathrm{H}_{1} \mathrm{H}_{2}, 10.4 \pm 2.8$ vs $\left.4.2 \pm 0.6, p=0.023\right)$, both men and women. Again, Bonferroni's correction did not alter these findings in most cases.

A comparison of patients with normoalbuminuria (NA), microalbuminuria and proteinuria is shown in Table 5. $P_{2}$ homozygotes were $170 \%$ more likely to have MA or proteinuria, O.R. $2.7(1.6-4.5, p=0.0001)$, 
Table 4. PvuII and HindIII polymorphisms and Albumin: Creatinine ratio, including proteinurics

\begin{tabular}{|c|c|c|c|c|}
\hline & \multicolumn{4}{|c|}{$\mathrm{ACR}(\mathrm{mg} / \mathrm{mmol} \mathrm{Cr})$ means $\pm \mathrm{SEM}$} \\
\hline & $P_{1} P_{1}$ & $P_{1} P_{2}$ & $P_{2} P_{2}$ & $P_{1} P_{1}+P_{1} P_{2}$ \\
\hline Whole cohort & $8.1 \pm 2.4$ & $4.8 \pm 1.0$ & $12.6 \pm 3.5$ & $6.0 \pm 1.1^{\mathrm{a}}$ \\
\hline Caucasians & $8.0 \pm 3.3$ & $4.6 \pm 1.3$ & $10.8 \pm 3.6$ & $5.8 \pm 1.4^{b}$ \\
\hline Male Caucasians & $6.1 \pm 2.3$ & $5.7 \pm 2.2$ & $14.2 \pm 6.7$ & $5.8 \pm 1.7 \mathrm{c}$ \\
\hline Female Caucasians & $10.3 \pm 6.6$ & $3.2 \pm 0.7$ & $7.2 \pm 1.6$ & $5.8 \pm 2.5^{\mathrm{d}}$ \\
\hline \multirow[t]{2}{*}{ Non Caucasian } & $8.2 \pm 3.2$ & $5.2 \pm 1.4$ & $17.6 \pm 8.8$ & $6.4 \pm 1.5$ \\
\hline & $H_{1} H_{1}$ & $H_{1} H_{2}$ & $\mathrm{H}_{2} \mathrm{H}_{2}$ & $H_{1} H_{1}+H_{1} H_{2}$ \\
\hline Whole cohort & $7.0 \pm 3.8$ & $6.4 \pm 1.9$ & $9.2 \pm 1.9$ & $6.4 \pm 1.7 \mathrm{e}$ \\
\hline Caucasians & $3.4 \pm 1.1$ & $4.3 \pm 0.7$ & $10.4 \pm 2.8$ & $4.2 \pm 0.6^{f}$ \\
\hline Male Caucasians & $4.7 \pm 2.3$ & $4.8 \pm 1.2$ & $11.3 \pm 4.1$ & $4.8 \pm 1.1$ \\
\hline Female Caucasians & $2.4 \pm 0.7$ & $3.8 \pm 0.7$ & $9.0 \pm 3.3$ & $3.6 \pm 0.6^{\mathrm{g}}$ \\
\hline Non Caucasian & $17.0 \pm 14.3$ & $10.9 \pm 6.0$ & $6.8 \pm 1.5$ & $11.7 \pm 5.5$ \\
\hline
\end{tabular}

a $P_{1} P_{1}+P_{1} P_{2}$ vs $P_{2} P_{2}$ (208 vs 94), $p<0.0001$

b $P_{1} P_{1}+P_{1} P_{2}$ vs $P_{2} P_{2}(139$ vs 69$), p=0.0001(p=0.0005)$

${ }^{c} P_{1} P_{1}+P_{1} P_{2}$ vs $P_{2} P_{2}$ (79 vs 36$), p=0.005(p=0.02)$

d $P_{1} P_{1}+P_{1} P_{2}$ vs $P_{2} P_{2}(60$ vs 33$), p=0.01(p=0.04)$

e $H_{1} H_{1}+H_{1} H_{2}$ vs $H_{2} H_{2}(139$ vs 164$), p=0.02$
${ }^{\mathrm{f}} H_{1} H_{1}+H_{1} H_{2}$ vs $H_{2} H_{2}$ (97 vs 112$), p=0.023(p=0.09)$

g $H_{1} H_{1}+H_{1} H_{2}$ vs $H_{2} H_{2}$ (47 vs 47$), p=0.026(p=0.1)$

Values in brackets are corrected for multiple analyses with Bonferroni's correction

Table 5. PvuII polymorphisms by presence of microalbuminuria and proteinuria

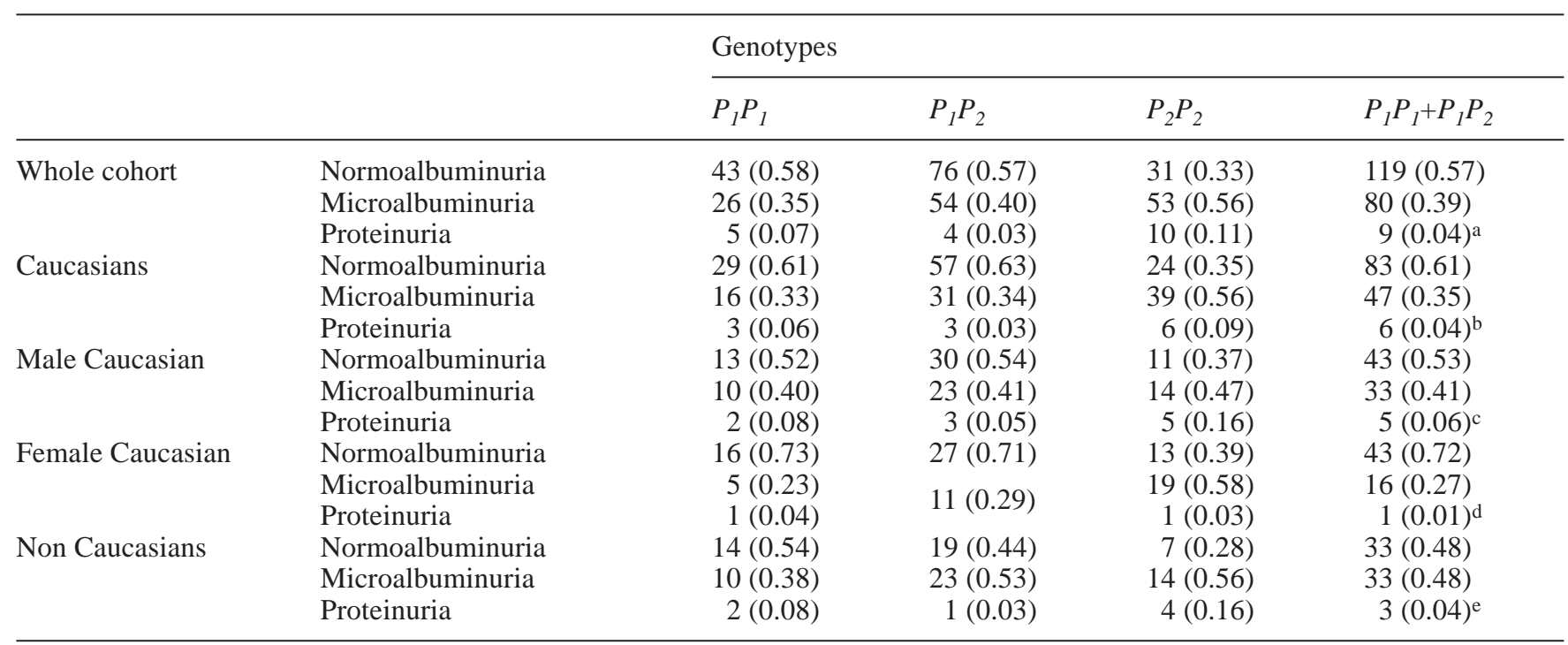

${ }^{\text {a }} P_{1} P_{1}+P_{1} P_{2}$ vs $P_{2} P_{2}$ (NA vs MA+P), O.R.=2.7 (1.6-4.5) $p=0.0001$

$P_{1} P_{1}+P_{1} P_{2}$ vs $P_{2} P_{2}$ (NA vs MA), O.R.=2.5 (1.5-4.3) $p=0.001$

$P_{1} P_{1}+P_{1} P_{2}$ vs $P_{2} P_{2}$ (NA vs P), O.R.= $4.3(1.6-11.4) p=0.004$

b $P_{1} P_{1}+P_{1} P_{2}$ vs $P_{2} P_{2}$ (NA vs MA+P), O.R.=3.0 (1.7-5.6) $p=0.0003(p=0.0012)$

${ }^{c} P_{1} P_{1}+P_{1} P_{2}$ vs $P_{2} P_{2}$ (NA vs MA+P), O.R.=2.7 (1.2-6.3) $p=0.017(p=0.068)$

$150 \%$ more likely to have MA, O.R. 2.5 (1.5-4.3, $p=0.001$ ), and $330 \%$ more likely to have proteinuria, O.R. 4.3 (1.6-11.4, $p=0.004)$. This observation was true for Caucasians, with a similar trend in non-Caucasians. When Bonferroni's correction is applied, the results for male Caucasians and non-Caucasians lose significance.

Previous data suggests that the $L P L$ gene could be associated with hypertension [39], which in turn is a d $P_{1} P_{1}+P_{1} P_{2}$ vs $P_{2} P_{2}$ (NA vs MA+P), O.R.=3.9 (1.6-9.5) $p=0.002(p=0.008)$

${ }^{\text {e }} P_{1} P_{1}+P_{1} P_{2}$ vs $P_{2} P_{2}$ (NA vs P), O.R.=6.3 (1.1-34.6) $p=0.02$ $(p=0.08)$

Values in brackets are corrected for multiple analyses with Bonferroni's correction

recognised risk factor for MA [5] thus the data was analysed with respect to blood pressure. There were no differences in BP between the various genotypes $\left(P_{2} P_{2}\right.$ vs $P_{1} P_{1}+P_{1} P_{2}, 140.1 / 82.1$ vs $136.6 / 78.9$ vs $140.1 / 78.1),\left(H_{1} H_{1}\right.$ vs $H_{1} H_{2}$ vs $H_{2} H_{2}, 130.9 / 75.5$ vs $138.7 / 79.9$ vs $139.1 / 79.5)$.

Multiple regression analyses were done to test if the genotype associations with MA as a binary outcome (normoalbuminuria versus MA/proteinuria, Ta- 
Table 6. Multivariate analysis of known and suspected risk factors for presence of microalbuminuria/proteinuria by binary logistic regression

\begin{tabular}{|c|c|c|c|c|c|c|c|c|c|c|}
\hline & \multicolumn{5}{|c|}{ Whole Cohort } & \multicolumn{5}{|l|}{ Caucasians } \\
\hline & $\begin{array}{l}\text { Coefficient } \\
\text { value }\end{array}$ & $p$ & $\begin{array}{l}\text { Relative } \\
\text { risk }\end{array}$ & $\begin{array}{l}95 \%-\mathrm{CI} \\
\text { lower }\end{array}$ & $\begin{array}{l}95 \%-\mathrm{CI} \\
\text { upper }\end{array}$ & $\begin{array}{l}\text { Coefficient } \\
\text { value }\end{array}$ & $p$ & $\begin{array}{l}\text { Relative } \\
\text { risk }\end{array}$ & $\begin{array}{l}95 \%-\mathrm{CI} \\
\text { lower }\end{array}$ & $\begin{array}{l}95 \%-\mathrm{CI} \\
\text { upper }\end{array}$ \\
\hline Age (years) & -0.05 & 0.70 & 0.99 & 0.97 & 1.02 & 0.002 & 0.90 & 1.00 & 0.97 & 1.03 \\
\hline Sex & 0.32 & 0.26 & 0.73 & 0.42 & 1.26 & 0.44 & 0.22 & 0.64 & 0.32 & 1.30 \\
\hline Systolic BP (mmHg) & 0.02 & 0.008 & 1.02 & 1.01 & 1.04 & 0.03 & 0.006 & 1.03 & 1.01 & 1.06 \\
\hline Duration diabetes (years) & 0.02 & 0.43 & 1.02 & 0.98 & 1.05 & 0.03 & 0.31 & 1.03 & 0.98 & 1.08 \\
\hline $\mathrm{HbA}_{1}(\mathrm{~g} / \mathrm{L})$ & 0.07 & 0.21 & 1.07 & 0.96 & 1.19 & 0.21 & 0.004 & 1.23 & 1.07 & 1.42 \\
\hline Cholesterol (mmol/L) & -0.18 & 0.11 & 0.83 & 0.67 & 1.04 & -0.16 & 0.25 & 0.85 & 0.65 & 1.12 \\
\hline HDL-C $(\mathrm{mmol} / \mathrm{l})$ & -0.58 & 0.18 & 0.56 & 0.25 & 1.29 & -0.56 & 0.31 & 0.57 & 0.19 & 1.69 \\
\hline Triglyceride (mmol/l) & 0.06 & 0.61 & 1.06 & 0.85 & 1.31 & 0.06 & 0.68 & 1.06 & 0.81 & 1.37 \\
\hline Creatinine $(\mathrm{mg} / \mathrm{dl})$ & 0.12 & 0.031 & 1.01 & 1.01 & 1.03 & 0.02 & 0.042 & 1.02 & 1.00 & 1.03 \\
\hline
\end{tabular}

Table 7. Multivariate analysis of known and suspected determinants of ACR by linear regression

\begin{tabular}{|c|c|c|c|c|}
\hline & \multicolumn{2}{|l|}{ Whole Cohort } & \multicolumn{2}{|l|}{ Caucasians } \\
\hline & Coefficient value & $p$ & Coefficient value & $p$ \\
\hline Sex & 0.18 & 0.003 & 0.13 & 0.07 \\
\hline Systolic BP (mmHg) & 0.16 & 0.057 & 0.13 & 0.17 \\
\hline Diastolic BP (mmHg) & -0.17 & 0.035 & -0.07 & 0.39 \\
\hline $\mathrm{HbA}_{1}(\mathrm{~g} / \mathrm{l})$ & 0.05 & 0.38 & 0.15 & 0.022 \\
\hline Cholesterol (mmol/l) & -0.03 & 0.64 & 0.01 & 0.85 \\
\hline HDL-C (mmol/l) & -0.08 & 0.27 & -0.13 & 0.10 \\
\hline Triglyceride (mmol/L) & 0.05 & 0.46 & 0.10 & 0.21 \\
\hline Creatinine $(\mathrm{mg} / \mathrm{dl})$ & 0.17 & 0.005 & 0.26 & $<0.0001$ \\
\hline Pvu II & 0.19 & 0.002 & 0.32 & $<0.0001$ \\
\hline
\end{tabular}

ble 6), and ACR as a continuous variable (Table 7), were independent of confounding factors. Known and suspected risk factors for development of MA were analysed: age, sex, duration of diabetes, smoking, systolic $\mathrm{BP}$, diastolic $\mathrm{BP}, \mathrm{HbA}_{1}$, total cholesterol, HDL-C, triglyceride, creatinine and Pvu II polymorphism. 159 patients had a complete set of all variables tested, although data was over $90 \%$ complete for nine of the above variables. History of smoking (26.4\% incomplete data) and duration of diabetes (29.3\% missing data) were the only variables requiring substantial substitution for missing data. Binary analysis of the full cohort demonstrated that only systolic BP $(p=0.008)$, serum creatinine $(p=0.031)$ and $P_{2} P_{2}$ genotype had independent association with presence of MA/proteinuria, with $P_{2} P_{2}$ individuals being $68 \%$ more likely to have MA/proteinuria, O.R. 1.68
$(1.26-2.23, p=0.0004)$. When this analysis was repeated for Caucasians alone, systolic BP $(p=0.006)$, $\mathrm{HbA}_{1}(p=0.004)$, serum creatinine $(p=0.042)$ and $P_{2} P_{2}$ genotype had independent association with MA/proteinuria, with $P_{2} P_{2}$ individuals being $92 \%$ more likely to have MA/proteinuria, O.R. 1.92 $(1.33-2.75, p=0.0005)$.

Linear regression analysis of ACR as a quantitative trait (Table 7) demonstrated that for the whole cohort, sex $(p=0.003)$, diastolic BP $(p=0.035)$, creatinine $(p=0.002)$ and Pvu II genotype $(p=0.005)$ were independently predictive of degree of ACR, with systolic BP showing a trend $(p=0.057)$. Analysis of the Caucasian subgroup showed that only $\mathrm{HbA}_{1}$ $(p=0.0022)$, creatinine $(p<0.0001)$ and Pvu II genotype $(p<0.0001)$ were independently predictive of ACR. 


\section{Discussion}

We found that single nucleotide polymorphisms in introns 6 (Pvu II) and 8 (Hind III) in the LPL gene associate with the presence and degree of microalbuminuria in Type II diabetic patients. This relationship with the $P_{2} P_{2}$ genotype appears independent of other risk factors, including lipids. Despite our observations with these non-coding (intronic) polymorphisms, we did not find any association between microalbuminuria and the coding (exonic) mutations Asp9 ${ }^{9}$-Asn, Asn ${ }^{291}$-Ser and Ser ${ }^{447}$-Ter.

The absence of an association of Asn ${ }^{291}$-Ser with microalbuminuria in our study is in keeping with the previous report in Type I diabetic nephropathy [37] but our observations with the Hind III and Pvu II polymorphisms do not agree with their conclusions, though the investigators did not study these intronic markers. Our data could be explained by the higher heterozygosity of the intronic polymorphisms that we investigated, as they are more informative when investigating polygenic diseases [40, 41]. Our intronic polymorphisms had heterozygosity indices of 0.498 and 0.375 , while the exonic mutations had indices of $0.02,0.075$ and 0.18 . Thus it is not unexpected that our observations with the $R_{2}$ allele of the Asn ${ }^{291}-$ Ser mutation (prevalence of $1 \%$ amongst total cohort, $2 \%$ of Caucasians) were similar to that previously reported in a similar sized cohort of Type I diabetic patients [37]. The observations with the more prevalent intronic polymorphisms might not have translated into associations with the exonic polymorphisms because the latter occur at substantially lower frequency. It is therefore unlikely that the power of our study is sufficient to explore these specific exonic mutations fully, although it was adequately powered to evaluate the relationship of the gene with microalbuminuria utilising the intronic polymorphisms.

Our data concerning mean ACR concentrations and genotypes best fits a recessive pattern of inheritance for the effects of the LPL gene upon urinary albumin excretion in our cohort. Further examination of our subjects with albumin excretion considered in three standard categories, showed that $P_{2}$ homozygotes for the recessive alleles were significantly less likely to have normoalbuminuria than those subjects with alternative genotypes, providing additional support for this mode of transmission. However, our findings are less clear when including patients with albumin excretion in the proteinuric range, as our data is skewed by a minority of individuals with markedly higher concentrations.

In view of the fact that certain of the polymorphic alleles examined were in linkage disequilibrium, the examination of haplotypes would provide a powerful tool to investigate this gene. However, given the number of polymorphic variants that we investigated and the large number of haplotypes these would generate, such analyses were beyond the scope of our study, which did not have the statistical power or design to undertake such a task.

A new candidate gene for the development and progression of microalbuminuria in Type II diabetes therefore emerges from our data and supports a direct role for lipids/lipoproteins in this disease process. Although the $P_{2}$ allele was independently associated with microalbuminuria, it is worth noting that LPL variants have previously been shown to correlate with development and severity of coronary artery disease [24, 25, 26, 33], hence the association of $P_{2}$ with MA could, in part, be derived from the independent relationship of LPL genotypes and microalbuminuria with cardiovascular disease.

Higher concentrations of total cholesterol, LDL cholesterol, triglycerides and apo-B have all previously been correlated with either progression to micro/macroalbuminuria or deterioration in renal function in both Type 1 and Type II diabetic patients [20, $21,42,43]$. Possible mechanisms for an effect of lipids and lipoproteins on diabetic nephropathy could include mesangial cell proliferation, recruitment of macrophages, cytokine responses and matrix deposition [15]. The association between global glomerulosclerosis and atherosclerosis has been noted previously [44] and the presence of foam cells in multiple chronic inflammatory diseases, including atherosclerosis and many glomerulopathies, suggests a common pathogenesis. Evidence suggests foam cells are derived by the de-regulated uptake of modified LDL by scavenger receptors on macrophage/monocytes and mesangial cells $[45,46]$. Foam cell formation is also promoted by triglyceride-rich lipoproteins, most notably VLDL. Given, that both clearance of triglyceride-rich lipoproteins and LDL generation are influenced by lipoprotein lipase activity, this enzyme could play a key role in the mesangial cell pathology.

Hypertension is known to be a risk factor for diabetic nephropathy [5], thus our observation that systolic BP was also an independent predictor for microalbuminuria was expected. It is now well established that lowering BP attenuates microalbuminuria in Type II diabetes, with specific agents such as angiotensin converting enzyme inhibitors and angiotensin II receptor blockers conferring superior benefit in certain patients, when compared to other agents with comparable blood pressure reductions. Therefore early targeting of patients at highest risk of developing DN could be important in the future. Identification of individuals at genetically higher risk could also be important in targeting more aggressive management of dyslipidaemia as well as other risk factors. To help clarify the relationship between LPL, lipoproteins and DN, further examination of underlying mechanisms and confirmation of our observations in larger prospective studies could be appropriate, which could proceed to interventional trials using lipid modifying pharmacotherapy. 
A strength of this study is that the cohort of patients was specifically and sequentially recruited from a routine diabetic clinic and is therefore likely to reflect risk factor prevalence and clinical practice in the UK. Weaknesses include the use of spot urine samples for ACR, which we recognise is not as robust a quantitative measure of MA as a timed urine collection for calculation of albumin excretion rate (AER). However, spot ACR and AER are highly correlated [47]. The former is therefore commonly accepted for the derivation of an estimated AER, particularly as the day-today variation in AER could be as large as the imprecision of the derivation [48]. We used ACR because at the time of the earliest measurements for microalbuminuria, ACR was the routine investigation in our clinic. Association studies are also known to suffer from type 1 errors which must be borne in mind when interpreting the data.

Our observations suggest that genetic variation in the lipoprotein lipase gene could be important in the development and progression of diabetic nephropathy, and support the role of lipoprotein metabolism in this process. The relative importance of lipid and lipoprotein metabolism to other recognised risk factors merits further consideration. It could also be appropriate to evaluate our findings in the full range of diabetic renal disease, in order to identify potential mechanisms by which dyslipoproteinaemia influences renal function.

Acknowledgements. We would like to thank the Statistical Consultancy Unit, Department of Statistics, University of Warwick for their assistance. R.K. Mattu is supported by the British Heart Foundation, J. Trevelyan by the National Heart Research Fund, EWAN by the British Heart Foundation, D. Richter by the European Society of Cardiology.

\section{References}

1. Viberti G, Walker J, Pinto J (1992) Diabetic nephropathy. In: Albert K, DeFronzo R, Keen H, Zimmet P (eds) International textbook of diabetes mellitus. John Wiley, Chichester, pp 1267-1328

2. Keen H, Chlouverakis C, Fuller J, Jarrett RJ (1969) The consomitants of raised blood sugar: studies in newly-detected hyperglycaemics. II. Urinary albumin excretion, blood pressure and their relation to blood sugar levels. Guys Hosp Rep 118:247-254

3. Viberti GC, Pickup JC, Jarrett RJ, Keen H (1979) Effect of control of blood glucose on urinary excretion of albumin and beta 2 microglobulin in insulin-dependent diabetes. $\mathrm{N}$ Engl J Med 300:638-641

4. Viberti G, Hill R, Jarrett R, Argyropoulos A, Mahmud U, Keen H (1982) Microalbuminuria as a predictor of clinical nephropathy in insulin-dependent diabetes mellitus. Lancet i: $1430-1432$

5. Mogensen CE, Christensen CK (1984) Predicting diabetic nephropathy in insulin-dependent patients. N Engl J Med 311:89-93

6. Mogensen C (1984) Microalbuminuria predicts clinical proteinuria and early mortality in maturity-onset diabetes. N Engl J Med 310:356-360
7. Krowlewski AS, Warram JH (1991) Natural history of diabetic nephropathy in NIDDM. In: Pickup JC, Williams G (eds) Textbook of Diabetes. 2nd edn. Blackwell Science, Oxford pp 53.10-53.11

8. Messent JWC, Elliott TG, Hill RD, Jarrett RJ, Keen H, Viberti GC (1992) Prognostic significance of microalbuminuria in insulin-dependent diabetes mellitus: a twentythree year follow-up study. Kidney Int 41:836-839

9. Dinneen SF, Gerstein HC (1997) The association of microalbuminuria and mortality in non-insulin dependent diabetes mellitus. Arch Intern Med 157:1413-1418

10. Nelson R, Knowler W, Pettitt D, Bennett P (1995) Kidney disease in diabetes. In: Diabetes in America. 2nd edn. National Institute of Diabetes and Digestive and Kidney Diseases, NIH publication No. 95-1468, Bethesda, pp 349400

11. Seaquist ER, Goetz FC, Rich S, Barbosa J (1989) Familial clustering of diabetic kidney disease. Evidence for genetic susceptibility to diabetic nephropathy. New Engl JMed 320:1161-1165

12. Viberti GC, Keen H, Wiseman MJ (1987) Raised arterial pressure in parents of proteinuric insulin dependent diabetics. BMJ 295:515-517

13. Pettitt DJ, Saad MF, Bennett PH, Nelson RG, Knowler WC (1990) Familial predisposition to renal disease in two generations of Pima Indians with Type II (non-insulin-dependent) diabetes mellitus. Diabetologia 33:438-443

14. Moorhead JF, Chan MK, El-Nahas M, Varghese Z (1982) Lipid nephrotoxicity in chronic progressive glomerular and tubulo-interstitial disease Lancet ii:1309-1311

15. Keane WF (1994) Lipids and the kidney. Kidney Int 46: 910-920

16. Mascio G, Oldizzi L, Rugiu C, De Biase V, Loschiaro C (1991) Effect of dietary manipulation on the lipid abnormalities in patients with chronic renal failure. Kidney Int 39 [Suppl 31]:70-72

17. Capelli P, Evangelista M, Bonomini M, Palmieri P, Albertazzi A (1992) Lipids and the progression of chronic renal failure. Nephron 62:31-35

18. Samuelsson O, Aurell M, Knight-Gibson C, Alaupovic P, Attman PO (1993) Apolipoprotein-B-containing lipoproteins and the progression of renal insufficiency. Nephron 63:279-285

19. Samuelsson O, Mulec H, Knight-Gibson C et al. (1997) Lipoprotein abnormalities are associated with increased rate of progression of human chronic renal insufficiency. Nephrol Dial Transplant 12:1908-1915

20. Mulec H, Johnsen SA, Wiklund O, Bjorck S (1993) Cholesterol: a renal risk factor in diabetic nephropathy? A J Kidney Dis 22:196-201

21. Gall M-A, Hougaard P, Borch-Johnsen K, Parving H-H (1997) Risk factors for development of incipient and overt diabetic nephropathy in patients with non-insulin dependent diabetes mellitus: prospective, observational study. BMJ 314:783-788

22. Samuelsson O, Attman PO, Knight-Gibson C et al. (1998) Complex apolipoprotein B-containing lipoprotein particles are associated with a higher rate of progression of human chronic renal insufficiency. Am Soc Nephrol 9:1482-1488

23. Eckel RH (1989) Lipoprotein lipase. A multifunctional enzyme relevant to common metabolic diseases. N Engl J Med 320:1060-1068

24. Mattu RK, Needham EW, Morgan R et al. (1994) DNA variants at the LPL gene locus associate with angiographically defined severity of atherosclerosis and serum lipoprotein levels in a Welsh population. Arterioscler Thromb 14:1090-1097 
25. Mattu RK, Needham EWA, Laban C, Sweetnam P, Yarnell J, Galton DJ (1997) A common mutation of the lipoprotein lipase gene protects against coronary artery disease in the Caerphilly Heart Study. Atherosclerosis 135:11

26. Thorn JA, Chamberlain JC, Alcolado JC et al. (1990) Lipoprotein and hepatic lipase gene variants in coronary atherosclerosis. Atherosclerosis 85:55-60

27. Stocks J, Thorn JA, Galton DJ (1992) Lipoprotein lipase genotypes for a common premature termination codon mutation detected by PCR-mediated site-directed mutagenesis and restriction digestion. Lipid Res 33:853-857

28. Chamberlain JC, Thorn JA, Oka K, Galton DJ, Stocks J (1989) DNA polymorphisms at the lipoprotein lipase gene: associations in normal and hypertriglyceridaemic subjects. Atherosclerosis 79:85-91

29. Mailly F, Fisher RM, Nicaud V et al. (1996) Association Between the Lpl-D9n Mutation In the Lipoprotein-Lipase Gene and Plasma-Lipid Traits In Myocardial-Infarction Survivors From the Ectim Study. Atherosclerosis 122:21-28

30. Needham E, Sweetnam P, Laban C, Natt R, Yarnell J, Mattu R (1996) The lipoprotein lipase gene locus associates with serum HDL and APO- AI levels. Heart 75:164

31. Thorn JA, Needham EWA, Mattu RK, Stocks J, Galton DJ (1998) The Ser(447)-Ter mutation of the lipoprotein lipase gene relates to variability of serum lipid and lipoprotein levels in monozygotic twins. Lipid Res 39:437-441

32. Reymer PW, Gagne E, Groenemeyer BE et al. (1995) A lipoprotein lipase mutation (Asn291Ser) is associated with reduced HDL cholesterol levels in premature atherosclerosis. Nat Genet 10:28-34

33. Thorn JA, Needham EW, Mattu R, Chamberlain JC, Galton DJ, Stocks J (1991) Haplotypes At the LipoproteinLipase Gene Locus and Coronary Atherosclerosis In a Pedigree Based Study. Atherosclerosis 90:224

34. Reymer PWA, Groenemeyer BE, Gagne E et al. (1995) A Frequently Occurring Mutation In the Lipoprotein-Lipase Gene (Asn291ser) Contributes to the Expression Of Familial Combined Hyperlipidemia. Hum Mol Genet 4:1543-1549

35. Mailly F, Tugrul Y, Reymer PW et al. (1995) A common variant in the gene for lipoprotein lipase (Asp9->Asn). Functional implications and prevalence in normal and hyperlipidemic subjects Arterioscler Thromb Vasc Biol 15: 468-478

36. Benlian P, DeGennes JL, Foubert L, Zhang HF, Gagne SE, Hayden M (1996) Premature atherosclerosis in patients with familial chylomicronemia caused by mutations in the lipoprotein lipase gene. N Engl J Med 335:848-854

37. Hadjadj S, Gallois Y, Simard G et al. (2000) Lack of relationship in long-term type 1 diabetic patients between diabetic nephropathy and polymorphisms in apolipoprotein epsilon, lipoprotein lipase and cholesteryl ester transfer protein. Genetique de la Nephropathie Diabetique Study Group. Donnees Epidemiologiques sur le Syndrome d'Insulino-Resistance Study Group. Nephrol Dial Transplant 15:1971-1976

38. Zhang Q, Cavanna J, Winkelman BR et al. (1995) Common genetic variants of lipoprotein lipase that relate to lipid transport in patients with premature coronary artery disease. Clin Genet 48:293-298

39. Wu D-A, Bu X, Warden C et al. (1996) Quantitative trait locus mapping of human blood pressure to a genetic region at or near the lipoprotein lipase gene on chromosome 8p22. J Clin Invest 97:2111-2118

40. Botstein D, White RL, Skolnick M, Davis RW (1980) Construction of a genetic linkage map in man using restriction fragment length polymorphisms. Am J Hum Genet 32:314 331

41. Risch N, Merikangas K (1996) The future of genetic studies of complex human diseases. Science 273:1516-1517

42. Attman PO, Samuelsson O, Alaupovic P (1997) Progression of renal failure: role of apolipoprotein B-containing lipoproteins. Kidney Int 52 [Suppl 63]:S98-S101

43. Watts GF, Naumova R, Slavin BM et al. (1989) Serum lipids and lipoproteins in insulin-dependent diabetic patients with persistent microalbuminuria Diabet Med 6:25-30

44. Kasiske B (1987) Relationship between vascular disease and age-associated changes in the human kidney. Kidney Int 31:1153-1159

45. Steinberg D (1997) Lewis A. Conner Memorial Lecture. Oxidative modification of LDL and atherogenesis. Circulation 95:1062-1071

46. Goldstein JL, Brown MS (1990) Regulation of the mevalonate pathway. Nature 343:425-430

47. Gatling W, Knight C, Mullee M, Hill R (1988) Microalbuminuria in diabetes: a population study of the prevalence and an assessment of three screening tests. Diabet Med $5: 343-347$

48. Cundy T, Nixon D, Berkahn L, Baker J (1992) Measuring the albumin excretion rate: agreement between methods and biological variability. Diabet Med 9:138-143 